\title{
O corpo como base da ética na teoria da motricidade humana: o desporto como foco de análise
}

Fabio Zoboli

Professor da Universidade Federal de Sergipe

Doutor em Educação pela Universidade Federal da Bahia

Renato Izidoro da Silva

Professor da Universidade Federal do Amazonas

Doutor em Educação pela Universidade Federal da Bahia

Adolfo Ramos Lamar

Professor da Fundação Universidade Regional de Blumenau

Doutor em Educação pela UNICAMP

\section{Resumo}

A teoria da Motricidade Humana criada na década de 1980 pelo português Manuel Sérgio é uma presunção que tenta dar bases epistemológicas para criar um novo paradigma a fim de pautar as práxis da Educação Física. As bases da teoria se assentam numa perspectiva de corpo centrada na filosofia e ciências humanas para contrapor e somar as bases históricas das práxis da Educação Física historicamente fundadas no corpo anatomo-biológico. Neste sentido, o presente artigo tem como objetivo discutir a centralidade do corpo para a construção de uma base ética na teoria da Motricidade Humana. Para argumentar tal centralidade os autores estabelecem fundamentalmente um diálogo tensivo entre Nietzsche e Merleau-Ponty para fazer um paralelo de como Manuel Sérgio se apropria da filosofia de ambos para conceber o corpo enquanto dimensão ética na sua teoria.

Palavras-chave: Ética; Corpo; Motricidade Humana.

\section{Resumen}

La teoría de la motricidad humana criada en la década de 1980 por el portugués Manuel Sérgio trata de elaborar las bases epistemológicas de la creación de un nuevo paradigma que tiene como objetivo fundamentar la praxis de la Educación Física. Las bases de esta teoría se apoyan, principalmente, en una perspectiva del cuerpo de la filosofía y ciencias humanas para se contraponer y sumar a las bases históricas de la praxis de la Educación Física históricamente fundamentada en el cuerpo anatómico-biológico. El artículo tiene como objetivo discutir el carácter central de cuerpo en la construcción de una base ética de la teoría de la Motricidad Humana. Pretendiendo argumentar ese carácter central en el artículo se realiza un diálogo entre Nietzsche y MerleauPonty buscando colocar que Manuel Sérgio se apropria de la filosofía de ambos con el objetivo de concebir el cuerpo como dimensión ética en su teoría. 
Palabras-clave: Ética; Cuerpo; Motricidad Humana.

\section{Introdução à ética em Manuel Sérgio}

Eu não sigo o vosso caminho, desprezadores do corpo! Vós, para mim, não sois pontes que se encaminhem para o Super-

homem!

Assim falou Zaratustra (Nietzsche, 2005, p. 42).

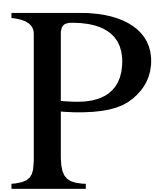

ara desenvolver nosso enunciado, devemos inicialmente considerar a ética como um exercício humano de reflexão acerca de todo e qualquer imperativo social moral - tu deves. Ela consiste em ser uma instância absoluta, pois aplicável a qualquer situação humana. Mais profundamente, o exercício ético possibilita ao humano avaliar sua situação, logo, saber dos elementos, que o cercando, o constitui; para assim compreender e medir as possíveis causas e efeitos de suas ações. Como bem lembra Saviani (1980, p. 39), segundo as ideias de Nietzsche, “[...] a palavra homem significa exatamente aquele que avalia”.

Portanto, para arriscarmos falar da relação entre ética, corpo e motricidade humana de qualquer ponto de vista; é imperativo realizar o exercício de situar eticamente a motricidade humana, para então localizarmos os imperativos que vêm constituindo suas estruturas - seus deveres - no sentido da preparação do corpo para efetivação cega das moralidades modernas. Sendo ainda que, neste trabalho, a ética não se limita às funções do espírito intelectual na atividade de abstrações metafísicas em prol da aplicação de algum sistema ético, o qual não passaria de um conjunto complexo de moralidades abstratas a serem impostas verticalmente do Estado sobre a população.

Se a ética fundamenta a reflexão acerca das ações imperativas, a vemos como um verdadeiro trabalho corporal de reflexão sobre a ação humana, onde o corpo também avalia seus riscos e seus desejos, já que a possibilidade da reflexão é localizada no liame entre realizar ou não algum imperativo moral, permitindo que o sujeito crie novas possibilidades para 
além dessa dicotomia. Em outros termos, compreendemos a ética como uma verdadeira Motricidade onde o corpo também deseja em prol da realização do humano, pois se trata de um exercício que impele o corpo a pensar, resistir, medir, sentir e avaliar o preço para si e para o outro, das inúmeras possibilidades de suas ações, no intuito de canalizar sua potência para um fim bom e belo.

A moral perpassa pela doutrinação e condicionamento do físico em prol de algum ideal extra-humano que sucumbi qualquer tipo de avaliação das consequências objetivas para si e para o outro, porque condiciona o corpo a cumprir com o imperativo abstrato custe o que custar, como se o próprio corpo não se importasse em sofrer. Aqui, Educação e Doutrinação Física se confundem, se misturam, se aprisionam de tal modo, que um dos maiores esforços da pedagogia moderna é educar sem doutrinar, tarefa até agora impossível. Quem sabe, porque o problema não parece ser apenas linguístico, mas estrutural, já que não existe Educação sem um pouco de Doutrinação e vice-versa. Enquanto que o plano da Motricidade entrega ao sujeito em sua corporeidade a assunção de seu próprio desejo em ritmo de potência, tal como concebe Nietzsche, segundo Manuel Sérgio (2003, p. 118), a ética do super-homem que diz “[...] <<eu quero>> e o querer inabalável é a razão da sua moral“. Em oposição à ética judaica, cristã e democrática do ocidente, que enfraquece nossa vontade de potência cuja ética “é a biológica”, portanto corporal e motriz.

Em publicação anterior (SILVA e ZOBOLI, 2007), por exemplo, analisamos que apesar da concepção da Igreja Católica Medieval acerca do corpo - da dimensão carnal - ter feito com que os sujeitos sucumbissem à realidade corporal do pecado, bem como exaltassem seu aspecto penitente e pagador como único modo de atingir o plano divino da existência, isto é, levar a alma aos céus; vemos o corpo aparecer como elemento irredutível de ligação e de poder entre o plano terrestre e o plano divino sob o qual o sujeito está quase sufocado. É pelo corpo e através dele que o fiel demonstra e prova sua Fé e a Igreja exerce seu poder, sendo que, a representação do corpo sofrido e penitente eleva a alma a Deus, tal como fez Cristo 
crucificado. Lembrando que sobre isso, Manuel Sérgio (2003, p. 118) recupera a ideia de Nietzsche que concebe a moral cristã como profundamente contaminada por um desejo de poder.

Não só a moral cristã, mas também toda a filosofia até então colocava o corpo numa condição inferior e suja. Na obra “A Gaia Ciência” Nietzsche denuncia a filosofia por ter esquecido o corpo ao longo da história:

Com bastante frequência, eu me perguntei se, calculando por alto, a filosofia até agora não foi em geral somente uma interpretação do corpo e um mal entendido sobre o corpo. Por trás dos mais altos juízos de valor, pelos quais até agora a história do pensamento foi guiada, estão escondidos malentendidos sobre a índole corporal, seja de indivíduos, seja de classes ou de raças inteiras. (NIETZSCHE, 2001, p. 190)

Nietzsche ainda alerta pela boca de Zaratustra: "Por trás de seus pensamentos e sentimentos, meu irmão, há um senhor mais poderoso, um guia, um desconhecido. Chama-se ‘eu sou’. Habita no seu corpo, é o seu corpo.” (NIETZSCHE, 2005, p. 26)

Com isso, afirmamos que até mesmo no interior de sistemas filosóficos que tratam o corpo como simples objeto limitador e maléfico do espírito humano, a realidade corporal se faz presente de modo central e indispensável, para os ideais que o despreza se afirmarem. No exemplo da Modernidade, o Estado também surge como agente moralizante e doutrinador do sujeito através do corpo quando este é tratado no interior de suas instituições - Escolas, Hospitais, Presídios, Hospícios - de modo a ser enquadrado, disciplinado e controlado conforme um sistema filosófico moralizante. Veremos, portanto, que se o sujeito não passa de uma construção abstrata e ideológica segundo interesses que buscam sua materialização, “o corpo é o lugar último do exercício e sofrimento do poder” (SILVA e ZOBOLI, 2007).

Recuperamos, então, a crítica que Foucault (1979, p. 5) realiza sobre o grande modelo de análise dos fenômenos socioculturais, próprio da modernidade parcialmente fundamentada nas relações simbólicas, significantes, signas, semióticas e linguísticas. Pois, no seu ponto de vista, a 
“[...] historicidade que nos domina e nos determina é belicosa e não linguística”. Portanto, o equivoco dos medievais e dos modernos foi crer que seus símbolos moralizantes eram suficientes para dominar o espírito a fim de que este conduzisse o corpo. De modo que, uma matéria sólida e concreta só pode ser dirigida e modelada por outra matéria de poder igual ou superior, mesmo que esta seja em parte uma objetivação das possibilidades mentais. Portanto, se a linguística doutrina o espírito, a belicosidade domina o corpo em um corpo-a-corpo entre guerreiros que lutam para sobreviverem na garantia da corporeidade e da motricidade.

Trilhando por essas vias, notamos que se evidencia a construção da ética em Manuel Sérgio como que seguindo a retomada do corpo esquecido pelos medievais e pelos modernos - seguindo o fluxo da crise dos paradigmas modernos relacionados às dimensões do humano, basicamente as da mente e as do corpo -; a partir de suas leituras de Nietzsche (SERGIO, 2003, p. 118) e Merleau-Ponty (Idem, 1999, p. 124), quando recuperam e constroem uma outra biologia corporal, mais carnal que teórica. Assim, Manuel Sérgio realiza um trabalho filosófico e epistemológico no contexto atual da Educação Física. O filósofo entreve diferentemente do corpo maquinicamente educável e doutrinável da Modernidade. Trata-se de um corpo que intenciona, deseja e sofre as consequências - mazelas e alegrias de suas ações. Portanto, um corpo que avalia seus pesares segundo sua realidade de desejo e necessidade; potência e fragilidade. Vemos surgir no horizonte um corpo ético ou uma ética do corpo. Há, portanto, uma reconstrução fenomenológica da existência humana segundo o plano das essências. Vislumbramos nesta cerzidura que o pensador em questão ressuscita o corpo coisificado desde Platão, colocando-lhe ou devolvendolhe sua essência na roupagem existente da motricidade.

A produção filosófica, epistemológica e biológica de um corpo existente na e pela motricidade, feita por Manuel Sérgio (1999, p. 125) a partir da fenomenologia de Merleau-Ponty, pode ser encontrada em sua afirmação de que entre “[...] a apercepção psicológico-natural e a apercepção fenomenológica, existe uma radical oposição, porque a 
fenomenologia é uma crítica radical da experiência, é a questão que indaga sobre a essência de experiência (SÉRGIO, 1999, p. 125). '[...] é captar de novo a intenção total'” (MERLEAU-PONTY, apud loc. cit.). Quando Merleau-Ponty (1999, p. 17) fala da história, questiona a ideia de Marx de que a mesma não caminha com a cabeça, e que da mesma forma, ela não deve pensar com os pés. “Ou, antes, nós não devemos ocupar-nos nem de sua ‘cabeça', nem de seus 'pés', mas de seu corpo”. Por quê? Porque no corpo há mais sentidos do que nossa vã filosofia desconfia. ${ }^{1}$ Ou como prefere Nietzsche (2005, p. 41): "Há mais razão no teu corpo do que na tua melhor sabedoria”. Algo a ser significado de que a razão corporal abriu espaço para o advento do espírito.

Sendo assim, se deve contar que no corpo há racionalidade - ou lógica - tanto quanto há irracionalidade, ambas em perfeita interação. Como menciona Nietzsche (2005, p. 41), instrumento “[...] do teu corpo é também a tua razão pequena, a que chamas de espírito: um instrumentozinho e um pequeno brinquedo da tua razão grande”. Portanto, enquanto um poço de contradições, de desejos contrários, de dores prazerosas e de alegrias doloridas, no corpo, “[...] as perspectivas se confrontam, as percepções se confirmam, um sentido aparece” (MERLEAU-PONTY, 1999, p. 18). Ponto da fenomenologia que conflui com a noção de corpo em Nietzsche (2005, p. 41), que o traz como sendo “[...] uma razão em ponto grande, uma multiplicidade com um só sentido, uma guerra e uma paz, um rebanho e um pastor”.

Não sendo simplesmente um lugar do sentido, mas que dá e sente em sua essência os possíveis sentidos das existências. Em suma, nas palavras de Manuel Sérgio (1999, p. 126) sobre as existências na essência, quer dizer que “[...] o Mundo está-em-mim, numa relação tão íntima, com a que existe entre todas as partes do meu corpo”. Pensando que o mundo aí em questão

\footnotetext{
${ }^{1}$ Neste ponto exato, a problemática freudiana adentra atravessando violentamente essa questão, de modo que, a gene do sentido da visão psicanalítica do psiquismo está guardada justamente no fato de que a consciência em sua acepção moderna não é capaz de saber da totalidade da corporeidade e da motricidade. Motivo que faz com que estas se manifestem por meio daquilo que Freud chamou de sintoma cujo sentido é inconsciente.
} 
diz sobre “[...] toda a realidade humana [ser] um mundo também, às coisas, aos factos, aos acontecimentos, à palavra, ao gesto, ao silêncio ilumina-os um sentido que se torna importante des-velar (sic)” (Ibidem, p. 124).

Com isso, a partir dos estudos da fenomenologia de Merleau-Ponty, vemos surgir o membro nietzscheano de Manuel Sérgio acerca da ética do sentido, à qual “[...] estamos todos condenados” (MERLEAU-PONTY, apud SÉRGIO, 1999, p. 125). Por quê? Ora, segundo Ferraz (2007, p. 95) porque o corpo em Merleau-Ponty (1992) é “[...] um agente ativo na produção da experiência. O corpo fenomenal volta-se para os estímulos objetivos e os investe com algum sentido prático, de modo a elaborar uma situação significativa”. Algo que se aproxima da noção de corpo em Nietzsche, que segundo Ramacciotti (2007, p. 85), “[...] abrange as atividades mentais ou psicológicas em todo o organismo”. Viés que permite Nietzsche (2005, p. 41) elaborar em Assim falou Zaratustra, que tudo “[...] é corpo e nada mais; a alma é apenas nome de qualquer coisa do corpo“. Deste modo, o corpo surge como “a grande razão” porque seus desejos não necessitam de justificativas metafísicas para se assumirem. Portanto, o corpo é em Nietzsche o verdadeiro super-homem, pois, conforme Manuel Sérgio (2003, p. 118) ele é aquele que diz: “eu quero”, sendo “[...] seu querer inabalável [...] a razão da sua moral”. Mais ainda, “[...] é o sentido do mundo. Desde que o super-homem queira, nasce o sentido” (Ibidem, p. $120)^{2}$.

Manuel Sérgio desperta então para nós, a ética corporal enquanto motricidade de produção de sentido - criação de mundos e realidades - que avalia o mundo dado - oferecido - pelo passado, pelo presente e pelo futuro. Caminha para uma extemporaneidade cujo tempo e o espaço é o corpo quem cria, é dele que dependem. Esboçando um pensamento ficcional, isso

\footnotetext{
${ }^{2}$ Em Motricidade humana: um paradigma emergente, Manuel Sérgio (1995:17) mais sobre o fato de o corpo - enquanto matéria - ser o lugar fundamental dos demais desdobramentos humanos. Argumenta ele que no pensamento contemporâneo - Nietzsche, Marx e Freud "[...] o Homem passa a entender-se já não como um ser-diante-do-Mundo, mas com um ser que é elemento do próprio Mundo. Ao defender-se, como em Marx, por exemplo, a préexistência da matéria em relação ao Homem e ainda o dogma de que tudo é matéria, incluindo a consciência de que não é outra coisa senão um seu derivado [...]”.
} 
se mostra se imaginarmos que só podemos transformar um dia de segundafeira em dia de domingo se aplicarmos nossas práticas corporais reservadas culturalmente a este àquele. A bem dizer, alguém pode questionar que uma atitude transformadora de tal natureza carregaria elementos da segunda-feira para o domingo criado, logo que não seria propriamente um domingo. Contudo, perguntamos: qual a diferença? É óbvio que não será um domingo comum, de modo que: todos os domingos são iguais? Fazer de uma segunda-feira um dia de domingo pode simplesmente tomar o caráter de um domingo diferente? Ou será uma segunda-feira diferente? Com roupas diferentes? Com movimentos diferentes? Com lugares diferentes?

Não importa! "No super-homem, a vontade de viver equivale à vontade de poder” (SÉRGIO, 2003, p. 120). Mas, como desistimos de sê-lo, quiçá porque a “[...] ética judaica, cristã e democrática promove a ralé e abocanha a vontade de inovar” (Ibidem, p. 118). Valendo perceber que a categoria tempo e espaço estão atrelados à vontade e à submissão de nossos corpos. Provando que o corpo derradeiro é também o primitivo lugar da existência. Entretanto, que na Modernidade isso tenha sido levado a sério na existência corporal segundo a ciência ou as ciências, sucumbindo à verdade aquilo que Merleau-Ponty (1999, p. 3) muito bem proclama: “Tudo aquilo que sei do mundo, mesmo por ciência, eu o sei a partir de uma visão minha ou de uma experiência do mundo sem a qual os símbolos da ciência não poderiam dizer nada”. Sendo por essa trilha que vemos novamente Manuel Sérgio (2003, p. 124) retornar Nietzsche para também “[...] contrapor ao individualismo moderno, decorrente de vários tipos de totalidades, o indivíduo, na forma de uma autêntica mônada, sem classe e sem sistema; ao definir o homem enquanto corporeidade [...]”. Pois, não há, “[...] em Nietzsche, uma história universal, pois cada Super-homem cria sua própria história” (Ibidem, p. 120).

Mas, não pensem que isso é fácil. O Zaratustra de Nietzsche (2005, p. 41) diz que por “[...] detrás dos teus pensamentos e sentimentos, meu irmão, há um senhor mais poderoso, uma guia desconhecido. Chama-se 'eu sou'. Havia no teu corpo; é o teu corpo”. E àqueles que pensam o ser humano a 
buscar sua transcendência, esta é a do próprio corpo dado, para um corpo lançado ao devir cuja transformação inerente não é do espírito, mas dele próprio. Trata-se do homem, que ao tentar se transfigurar no super-homem, investe intencionalmente no corpo próprio e em suas representações, para transcender seu presente. Ora, não há outro elemento histórico-sóciocultural mais emblemático para a união entre corpo e super-homem, do que o atleta. Quiçá, ao lado do penitente, este seja o extremo do saber que diz da transcendência carnal entre a dor e o prazer. Com a diferença de que o atleta não tem um céu abstrato para se espelhar. Seu espelho é ele próprio, o corpo que diz o quanto quer, o quanto necessita, o quanto pode e quais são seus pontos e modos a percorrer. Ou será que o céu abstrato do atleta é o simbolismo histórico do podium e da medalha?

Todavia, há aqui uma questão epistêmica a ser colocada. Que é o homem? A resposta para essa pergunta é a possibilidade de realizar o que realmente é desejado: como manipular isso que é o homem? Portanto, como acertadamente afirmou Merleau-Ponty (1999), o herói do momento é o Homem, logo, que também se trata de uma abstração daquilo que de fato se quer manipular rumo à transcendência, na medida em que, falar em homem é falar em alguma espécie de deus cuja transcendência acerca daquilo que se é não passa de uma construção teórica e religiosa. Obrigando, dessa maneira, a entrada do corpo em cena. Pois, a significação corpo trás uma noção de materialidade maior que a significação homem. Categoria já bem demarcada epistemologicamente, como bem esclarece Laplantine (1996, p. 54): "Será preciso esperar o século XVIII para que se constitua o projeto de fundar uma ciência do homem, isto é, de um saber não mais exclusivamente especulativo, e sim positivo sobre o homem”. Mas por que somente após o século XVIII? O mesmo autor responde com Foucault:

Antes do final do século XVIII [...] o homem não existia. [...] É uma criatura muito recente que o demiurgo do saber fabricou com suas próprias mãos, há menos de duzentos anos (...) Uma coisa em todo caso é certa, o homem não é o mais antigo problema, nem o mais constante que tenha sido 
colocado ao saber humano. O homem é uma invenção [...] E quão próximo talvez seja o seu fim (FOUCAULT, apud Ibidem, p. 55).

Com isso, só nos resta localizar novamente o pensamento de MerleauPonty citado anteriormente, e dizer que o problema não é o Homem, assim como era Lúcifer e Prometeu. Trata-se da significação Homem enquanto símbolo que remete naturalmente a uma outra coisa: aquilo que se deseja manipular mesmo, rumo à transcendência concreta. Que em termos teóricos, o herói, então, a ser abordado pode estar mais proximamente girando às voltas do Super-homem nietzscheano. Ou seja, a significação corpo. De modo que, histórica e epistemologicamente falando, “[...] da segunda metade do século XX em diante e até os nossos dias, a problemática existencialista e os diversos estruturalismos proclama, respectivamente, a morte de Deus (como já fizera Nietzsche) e a morte do homem” (SÉRGIO, 1995, p. 18). Assim, o que temos hoje são as “ciências do homem” (Ibidem, p. 19). Ou por que não, temos palavras em torno da significação homem.

Mas, o que intriga é a velha pergunta fundamental: o que é isso que desejamos tanto manipular em sua totalidade rumo à transcendência, mas que no máximo conseguimos nomear parcialmente ou equivocadamente? Isso quer dizer que o objeto que desejamos manipular nos escapa, e às vezes é esquecido pela distração e fascínio que tomamos sobre nossas próprias significações. O que nos leva a sonhar no plano do símbolo, mas fracassar no plano da transcendência material: o resultado final de tudo isso é a morte e o renascimento em outro estado, para o qual a significação química e física também já não mais altera ou transforma a facticidade a partir da qual a fenomenologia diz através de Merleau-Ponty (1999, p. 1) intencionar “[...] compreender o homem e o mundo [...]”, a fim de repor “[...] as essências na existência [...]”"

Então o problema com o qual Manuel Sérgio se depara diz das essências e das existências. E a figura do atleta é o que une ambas na medida em que se trata de uma corporeidade dotada de motricidade que tenta transcender sua presença. A essência é corporeidade e motricidade 
cuja existência é também corporeidade e motricidade que como tais rumam à transcendência devido à facticidade do devir propriamente material. A corporeidade e a motricidade atlética enquanto existência significada, que quanto mais nelas são repostas a corporeidade e a motricidade, mais transcendem seus estados presentes que já são passados. Quanto mais um atleta exercita um músculo, mais o devir está presente na matéria, mais a transcendência se faz evidente, porque se desfruta no tempo corrido uma nova posição, um novo lugar diferente do anterior, que rompe com o anterior, pois já não é mais o mesmo. E o músculo atlético está tão ligado a isso, que vemos na significação do fenômeno esportivo, a corporeidade e a motricidade ora experimentar a existência da posição bronze no podium, depois a posição prata, depois a posição ouro, depois a posição nostálgica do músculo atlético aposentado após também experimentar nenhum lugar no podium, pois só possui força para um quarto, quinto, sexto... lugar. O que leva a pensar que a corporeidade e a motricidade enquanto essência de ser e estar movimento, possuindo vontades de existência - transcendência - que não é a de progresso, mas sim a de ocupar cada momento um lugar diferente no tempo do devir. Vislumbra-se uma ética da corporeidade e da motricidade. Da mesma forma que outro lado verifica-se a emergência de uma nova significação no lugar das ciências do homem: a ciência da motricidade humana. Pois, o que sabemos de fato sobre aquilo que desejamos manipular rumo à transcendência, é que possui uma presença movente.

\section{O desporto e a motricidade em Manuel Sérgio}

O desporto em Manuel Sérgio é um subsistema de um sistema maior chamado Motricidade Humana. A teoria da motricidade humana, fundada por este filósofo português apresenta um novo olhar para a Educação Física. Para este autor as expressões Educação Física, preparação física, atividade física, mesmo que aceitas pelos grandes senhores deste paradigma, não 
passam de reduzidas partes de um todo bem mais complexo que é a motricidade humana.

Ao precisar o paradigma da Educação Física, Manuel Sérgio conclui que este termo carece de rigor científico por estar ultrapassado no que tange aos novos paradigmas propostos pela física moderna, além de alegar ser este um termo usado por uma tradição, um capricho corporativista ou uma imposição do poder. Este tema é centralmente debatido em uma de suas mais belas obras: Um corte epistemológico: da educação física à motricidade humana.

O desporto é uma práxis lúdico-agonística e corporal, institucionalizada e com regras e, como tal, transforma-se naturalmente em ato político, pois que são também coletivas ou sociais as suas causas e as suas consequências. Dentro da ontologia do desporto, Manuel Sérgio diz que difícil se torna entender um mundo de seres humanos, constituídos por indivíduos radicalmente isolados. Sem intersubjetividade, sem intercorporeidade, não há desporto. O adversário transforma-se assim, na pessoa que permite a prática desportiva. Sem ele, normalmente a competição não acontece (se bem que se pode competir tão-só consigo mesmo). E sem competição (regulamentada) não há desporto.

O que é desporto então, segundo Manuel Sérgio? Certamente, um dos aspectos da motricidade humana. Na conduta motora (ação) desportiva, há uma referência constante a valores básicos, que a justificam e fundam. Daí, a dimensão fundamentalmente gnosiológica e axiológica da prática desportiva. Fazer desporto já é em si um comportamento ético. Porque o desporto só o é verdadeiramente quando assume o ser humano na integralidade das suas funções e potencialidades. O desporto há de ser também invenção de novas existências em novos valores, em nova ciência e nova tecnologia, em nova racionalidade comunicativa.

São nítidas as críticas deste intelectual ante os modos que a Educação Física concebe o ser humano e o desporto, assim como é nítida sua postura frente ao comprometimento e a responsabilidade que a Educação Física 
precisa adotar junto à promoção da dignidade humana - dignidade esta compreendida a partir da constante (re)construção da complexidade e transcendência humana. Para Manuel Sérgio o ser humano e o desporto transcendem as concepções biologizantes, concepções estas por demais impregnadas na Educação Física e na visão de ser humano.

Para Sérgio (2003, p.18-10):

Se o desporto é jogo, é competição, é pedagogia, é enfim motricidade humana (entendida a motricidade humana como a energia para o movimento intencional da transcendência ou da superação), (sic) pode haver nele um desafio à profecia, um desafio à participação, um desafio ao primado do ser e um desafio a profundidade de vida, assuma ele as formas que assumir, desde a escola até ao desporto federado e passando pelo desporto para populações especiais.

O autor enumera no fenômeno desportivo todos estes desafios por acreditar que ele traz em sua essência relações extremamente íntimas com a própria condição da existência humana. O desporto é espetáculo, é mito, é movimento, é expressão, enfim, o desporto é isso e muito mais, ele é uma entidade apresentada ao ser humano onde o mesmo pode buscar seu melhor devir, onde ele pode transcender-se.

Estes ideais ficam ainda mais claros quando Manuel Sérgio menciona compreender o progresso desportivo não tendo como base o crescimento do número de praticantes, nem a consecução de espantosas aptidões e habilidades físicas, nem o aumento visível do numero de espectadores apaixonados. No seu entender só há progresso desportivo quando a qualidade preside a quantidade, quando o ser se antepõe ao ter. Enfim, “[...] o que vale dizer que o problema crucial em que o desporto se debate não está na opção entre continuar ou impedir o progresso que aí está, mas em orientá-lo noutra direção” SÉRGIO (2003, p. 88). Valendo destacar que essa outra direção se opõe ao sonho "pós-natural ou artificial” do cyborg e da inteligência artificial, em relação aos quais os sujeitos humanos propriamente carnais e mortais costumam depositar esperanças da vida eterna e da indestrutibilidade corporal, realizando-se no outro que não é ele próprio - humano -, mas uma criação do sonho de si. Ou seja, mesmo que o 
cyborg seja a realização material de um sonho de si, os sujeitos humanos permanecem se acreditando estarem na miséria do corpo por não poderem experimentar o ser cyborg nem em si e nem por meio de seu semelhante: o que poderia ser uma saída mais consoladora, já que, como argumenta Manuel Sérgio (2003, p. 56): “A humanidade do ser humano pressupõe uma nítida abertura a uma alteridade, quero eu dizer: à transcendência, quase sempre corporizada na pessoa de outro ser humano”.

Epistemologicamente, a motricidade humana orienta o corpo do atleta diferentemente do que faz a educação física com ele. No contexto desta última, impera o positivismo em que o corpo é o objeto/máquina onde se aplicam teorias e ideologias. Ao passo que, a perspectiva que a primeira oferece enquanto um novo paradigma concebe e vive o corpo enquanto sujeito que está no mundo enquanto que o mundo está também nele em relação de interdependência sob a égide da intencionalidade que permite a cada um dizer sim, como dizer não aos enquadramentos teóricos. Manuel Sérgio (2003, p. 51) salienta “[...] a autonomia e nunca a dependência”. Portanto, a transcendência não é buscada em Deus ou no cyborg, “[...] porque é também uma dimensão essencial do ser humano”. Com o acréscimo de que uma “[...] competição desportiva deve ser entendida como o <<oitavo dia da criação>>, dado que, nela, o praticante é uma tarefa a cumprir - uma tarefa onde a transcendência inevitavelmente acontece...” (Ibidem, p. 52). Sobre o exemplo do bailarino, Manuel Sérgio (Ibidem, p. 56) destaca a consideração de José Gil acerca da dança, onde “[...] encontra no corpo [...] 'uma multiplicidade de corpos virtuais'”. Logo, de transcendências.

Para exemplificarmos o que estamos tentando dizer, retomamos um momento em que Manuel Sérgio comenta a relação dos programas de treinamentos e os chamados gênios do desporto. “A lei do génio relembranos que nem tudo é sistema [...]” (SÉRGIO, 2003, p. 58). Para tanto, ele cita futebolistas como “[...] Di Stephano, Pelé, Maradona, Cruyjff, Platini [...]”. Nos quais não é possível encontrar a chave dessa classe de atletas “[...] tãosó nas virtualidades do modelo preconizado pelo treinador, mas também no 
facto único e irrepetível que era o gênio de cada um deles” (loc cit.). Em outros termos, a transcendência está presente na medida em que, por exemplo, podemos pensar que Pelé é uma significação transcendental de Edson Arantes do Nascimento, mas que não exprime outra coisa senão a essência na existência deste último que se exprime em Pelé, o Rei do futebol, no gênio de sua motricidade que ecoou para o plano extrajogo. Ou seja, se há uma retórica na motricidade de Pelé, ela não se dirigia apenas aos seus adversários. Pode-se dizer que os espectadores de Pelé driblavam com ele ao tempo que também eram driblados por ele junto aos oponentes.

Mais ainda, para falar de transcendência não podemos limitar Pelé ao seu "gênio da bola", ponto em que apreendemos uma de suas transfigurações transcendentais que possibilitaram e possibilitam tantas outras em inúmeras direções de significações: atleta do século, embaixador do futebol, o mito do esporte, a lenda viva do futebol, deus do futebol, o garoto pobre que virou Rei, etc. Bem como, pôde experimentar ser ator de cinema - incluindo um filme pedagógico sobre os fundamentos do futebol e cantor. Sua figura foi transformada em estátua - Rei Pelé -, instalada na entrada do estádio da Fonte Nova, em Salvador - BA. Foi Ministro dos Esportes do Governo de Fernando Henrique Cardoso entre os anos de 1995 e 1998. Possui até uma Lei com seu nome: Lei Pelé - Lei n. 9.615, de 24 de março de 1998. Enfim, o “[...] praticante desportivo não é fundamentalmente fisiologia, mas complexidade que subjectivamente (ou intersubjectivamente) se revela” (SÉRGIO, 2003, p. 58). “Como Rorty nos ensina”, diz Manuel Sérgio (apud, Ibidem, p. 60), “não se pode conhecer o que uma coisa é, (sic) independentemente das relações dessa coisa com outra coisa”. Neste sentido, considera-se:

A extensão do campo desportivo e a heterogeneidade dos elementos que o compõem fazem parte do tecido social e é deles que deveremos extrair os conceitos que nos permitam uma compreensão e explicação da prática desportiva (Idem, 1999, p. 247).

Em outros termos, Manuel Sérgio direciona a discussão fazendo questão sobre os modos de contato e apropriação do fenômeno esportivo. 
Sendo que, neste ponto, o mass media surge como elemento determinante até mesmo com respeito à essência do desporto, que é a motricidade. Portanto,

[...] se é verdade que a prática desportiva pode ser um protesto (e antídoto) vivo contra a civilização do homem sentado, [...] não é menos certo que a instrumentalização informativa do Desporto faz dele tão-só um espetáculo, onde as pessoas mais mediáticas nem sequer são os praticantes [...] (Ibidem, p. 252).

Considerando essencialmente que a questão da mediação em nossa sociedade da informação e da informática, não deve se confundir com o atual espetáculo da tecnologia que o mass media faz uso. Imagens via satélite lançadas em direção aos receptores domésticos para serem projetadas em telas de plasma, não é o que torna a relação do espectador com o mass media algo alienante. Na verdade, o elemento mediador em questão é muito antigo, é a palavra ou o que se diz sobre o fenômeno esportivo. Portanto, o esporte que conhecemos é o esporte falado ou escrito pelos chamados grandes meios de comunicação que nos dão impressão de estarmos mesmo participando dos problemas que envolvem a organização esportiva. O que faz os sujeitos substituírem a prática mesma pelo discurso da prática.

Medina (1990) considera que em uma sociedade de classes como a nossa, onde os meios materiais de comunicação estão nas mãos de interesses particulares, porém hegemônicos, “[...] a fala, a linguagem, apoiadas pelo raciocínio lógico-formal [...] parece mais bloquear do que abrir perspectivas para a compreensão do Universo como um todo” (MEDINA, 1990, p. 63). Dessa forma, o plano da expressão e do ocultamento, bem como a produção de sentido acerca de um fenômeno fica por conta das personagens do mass media que falam sem parar em um ritmo frenético e ininterrupto nos ouvidos e nas vistas do espectador que não é ouvido em contrapartida: “[...] as palavras são os signos das ideias do que fala” (FOUCAULT, apud SÉRGIO, 1999, p. 96). Para Manuel Sérgio (Ibidem, p. 256), a “[...] mediação aponta a importância decisiva dos agentes do Desporto na produção, recepção e transmissão de uma consciência crítica, que instrua a 
opinião pública sobre as contradições ocultas, nos programas de governo [...] e nos discurso dos dirigentes".

Pensar na transformação desse quadro é na verdade não pensar - no sentido clássico -, para cada um lançar-se diretamente na prática desportiva para que a noção mesma da totalidade seja construída com a vivência motriz - em ato - no corpo a corpo dessa realidade. Nesses termos, a apropriação deixa de ser meramente retórica e discursiva para se tornar algo antropofágico, onde a prática esportiva não se limita à atividade física no campo de jogo. Há que se jogar também os jogos políticos, históricos, culturais e econômicos que se joga atrás das câmeras de filmagem. Cujos adversários geralmente não vestem calção, chuteiras, joelheiras, caneleiras, raquetes, tacos... Mas, terno e gravata! Não jogam com bola, fitas, traves, redes, quimonos... Mas com canetas, papéis, letras, palavras, frases, dinheiro...

\section{Ética, educação física e desporto: apontamentos}

Em trabalho anterior, Benghi e Zoboli (2004, p. 61) colocaram em discussão a ética no exercício profissional da educação física. Considerando corporeidade e motricidade, ambos apresentam a Educação Física “[...] como uma ciência que cuida da realidade humana e aborda [...] questões éticas como a visão de ser humano e como complexidade [...]”. Neste sentido, consideramos hoje a necessidade de realizar uma distinção no texto do mencionado trabalho. Não se está falando aqui da Educação Física, segundo Manuel Sérgio (1999, p. 181), “[...] moderna, nascida em finais do século XVIII e princípios do século XIX, [que] traz consigo a concepção de Homem dividido em res cogitans e res extensa [...]”. Modernamente o corpo é concebido e tratado simplesmente como objeto de conhecimento da fisiologia e anatomia ao invés de sujeito conhecedor e crítico - questionador por excelência - dessas próprias ciências que falam teoricamente dele sem considerarem seu vínculo motriz com o exercício ético. 
Aos modos de Manuel Sérgio e sobre sua influência filosófica, os autores supracitados trazem à consciência uma Educação Física nada inocente ou simplesmente anátomo-fisiológica. Consideram-na como “[...] prática disciplinar e o importante papel que ela assume frente a (sic) formação humana para que [...] o (ser) humano possa mediar as relações com o mundo, com o outro e consigo mesmo [...]” (BENGHI e ZOBOLI, 2004, p. 61). Fazendo-nos assim pensar o quanto que a Educação Física em sua acepção moderna mediou nossa relação com nosso próprio corpo cultural - tanto singular quanto social. Por mais absurdo e espantoso que possa parecer, a Educação Física dos últimos anos educou sim nosso corpo: para conseguirmos permanecer o maior tempo possível, sentados em salas de aula; de fronte à televisão ou à espera de um leito no hospital para ouvir palavras de consolo de algum médico de plantão.

Sem dúvida, por meio dos métodos e princípios da Educação Física tradicional; fomos educados a temermos e desconhecermos nosso próprio corpo, bem como, a exemplo da Igreja, sermos punidos através do corpo com exercícios físicos de caráter militar: corridas e flexões de braços até exaustão. Ou por outro lado, a penitência corporal médica que se resolve na recomendação do repouso absoluto frente a qualquer aparente distúrbio anátomo-fisiológico. Foi basicamente assim que a disciplina em questão foi motivada pelas instâncias de poder em nossa sociedade que visavam a docilidade das vontades corporais e motrizes promovidas por exercícios físicos mascarados pelos chamados "fins em si mesmos", que escondiam - e escondem - os complexos políticos, econômicos e epistemológicos que aí estão atuando de modo invisível para maior parte dos sujeitos que entregam seus corpos aos chamados discursos competentes.

De maneira mais estrita, não há dúvida que nossa relação objetiva e subjetiva com o fenômeno esportivo fora em grande parte mediada e determinada pela Educação Física moderna, que enquanto mediadora pedagógica atua na base de nossa constituição humana graças à sua presença no contexto escolar. Dessa forma, a Educação Física Escolar fortemente marcada pelos ideais de competitividade, segregação e discriminação por 
meio do critério darwinista da seleção natural - os mais fortes e melhores sobrevivem -, mais a dicotomia cartesiana entre corpo e mente, que escraviza o corpo segundo ideais espirituais e intelectuais; é grande responsável por nossa passiva, limitada e parcial participação habitual no atual contexto sócio-cultural do esporte. Segundo Barros Neto (apud BENGHI e ZOBOLI, 2004, p. 35), isso faz lembrar que “[...] a Educação Física e o esporte no Brasil foram construídos historicamente sob a égide da doutrina liberal [...]”.

Quando Thomas Arnold (1795-1842) seguiu o fluxo da industrialização e urbanização da sociedade, adaptando e transformando os medievais jogos populares e burgueses à realidade da escola pública inglesa, mas principalmente no Colégio Rugby do qual foi diretor, através de novas regras e princípios, criou o esporte moderno fundamentado nas idéias do empirista, político e liberalista inglês, John Locke (1632-1704). Arnold estabeleceu contato com a obra Alguns pensamentos sobre educação, onde Locke afirmava, por causa de seu pensamento empirista, segundo Manuel Sérgio (1995, p. 81), “[...] que a educação corporal deveria ser anterior à educação do espírito”. Propositura que levou Thomas Arnold “[...] a persuadir [seus] alunos dos benefícios incontáveis de uma prática desportiva regular, metódica e por eles organizada. O educando ganha assim hábitos de vida saudável e responsável” (loc. cit.).

Uma vez na posse das regras dos jogos e dos métodos de treino, os rapazes até se treinam a eles mesmos. Formarão associações e orientá-las-ão à sua maneira. Tomarão conta das finanças dos clubes e administrá-las-ão, com seriedade. Fundaram um jornal e serão eles os diretores, os redatores, os administradores (VALSERRA, apud SÉRGIO, 1995, p. 82).

Torna-se inegável que Thomas Arnold reformulou e deu subsídios para uma radical mudança de hábito corporal dos jovens e da educação onde estavam inseridos, que até então seguiam os princípios da ginástica. É notável, portanto, que o novo hábito corporal nascente não pode ter como marca simplesmente a ausência de aparelhos, movimentos elaborados e determinados pelos professores, a ausência de ludicidade, a rigidez, o 
controle, próprios da ginástica que prezava militarmente pela ausência do acaso, do devir, do não planejamento dos movimentos, características essenciais do jogo desportivo, cujas regras são mais flexíveis e mutáveis. O novo hábito corporal dos estudantes, portanto, estabelecia o vínculo destes com esferas organizacionais da sociedade que anteriormente ficava em poder dos professores, diretores, supervisores etc. Através do desporto moderno, os movimentos corporais são retirados de seu isolamento anátomo-fisiológico e passa a influenciar a realidade política, econômica e cultural de uma sociedade.

Segundo Valserra (apud loc. cit.), o “[...] mundo do desporto, para Arnold, é um microcosmo, nem mais nem menos do que uma miniatura da sociedade”. Porém, hoje, podemos dizer que a tese de Arnold não se sustenta mais, já que o desporto há muito deixou de ser microcosmos para se transformar em elemento constituinte política, econômica e culturalmente da sociedade moderna. Mais ainda, Manuel Sérgio (loc. cit.) aponta que dois anos depois “dos primeiros jogos atléticos Oxford-Cambridge”, foi criando o “[...] Amateur Athelic Association, que admite tão-só, no seu seio, os endinheirados e os aristocratas, fechando ostensivamente as portas aos operários e a pessoas de 'baixa condição’”. Em 1867 surge também em Londres o primeiro jornal esportivo publicado na Europa, chamado The Athlete.

Disso tudo, interessa a nós destacar o caráter contraditório ou até mesmo paradoxal por que passou o desporto nas mãos da Educação Física. Se em princípio a prática desportiva que Arnold sugere na época tenta inserir os sujeitos - educandos - na vivência e entendimento da lógica da sociedade moderna, em um segundo momento o desporto é tornado mais um mecanismo da ideologia liberal para manter e criar novas demarcações materiais e simbólica das diferenças entre burgueses e proletários. O Amateur Athelic Association não deixa de ser um germe dos grandes clubes esportivos de hoje em dia, cuja ética é a do mascaramento da realidade política e econômica interna. Prática que acaba por excluir os associados e atletas profissionais de todo processo organizacional da realidade esportiva 
tal como Arnold preconizou como sendo um processo educativo para a atuação dos jovens na sociedade cultural, onde o habitus corporal não era limitado ao alienado ato em si de “jogar bola” destinado a promover uma saúde anátomo-fisiológica vegetativa.

Manuel Sérgio parece se aproximar de alguns caracteres preconizados por Arnold, mas sem se fundamentar nas arriscadas armadilhas democráticas do liberalismo. Se o desporto é uma manifestação da Motricidade Humana rumando à sua transcendência, a concepção biologicista e médica do corpo em ato, torna-o objeto em uma falsa essência, pois desencarnadamente teórica. Nas palavras de Medina (1990, p. 90), seguindo a revolução epistemológica empenhada por Manuel Sérgio, a transcendência deve ser entendida justamente “[...] como a capacidade peculiar da consciência de ir além das relações vegetativas, biológicas e naturais comuns aos demais seres vivos. [...] Neste sentido [devemos esforçar-nos] por interpretar as circunstâncias nas quais os fenômenos da corporeidade se manifestam”. Isto é, a situação em que o corpo se encontra com sua motricidade.

E qual é a situação do corpo motriz do atleta hodierno? Ora, o mass media enfatiza duas situações apenas: a de treino e a de competição. As complexidades do esporte parecem então se resumirem ao trabalho do sujeito/atleta enquanto relação de causa e efeito entre treino e resultado na competição. Assim, as problemáticas negativas ou positivas giram em torno de assuntos como tecnologia, métodos, técnicas e táticas de treino enquanto os verdadeiros e diretos influenciadores - variáveis - do rendimento do atleta da competição. Quando muito, o mass media se desloca para abrir algo sobre política e economia no esporte falando apenas da influência destes na parte infraestrutural e tecnológica dos treinamentos. Ou seja, o atleta é colocado como um sujeito impotente que sempre espera dos projetos políticos da macroestrutura - pública e/ou privada - enigmática e esotérica para ele. 
Diante disso, Manuel Sérgio (1999, p. 255) pergunta: “Qual é então a tese central a adiantar, na construção de uma teoria crítica do Desporto?” Ele mesmo responde: “o Desporto deve analisar-se como um processo $e$ uma prática sociais e, por isso, o Ter e o Poder nele se inscrevem no discurso e nas atitudes dos agentes desportivos”. Ou seja, isso deve ser sabido! Sem embargo, deve ser sabido também o fato de que “[...] não é fácil uma mentalidade desportiva nova” (Ibidem, p. 262). Dessa maneira, Manuel Sérgio aponta para um realismo sóbrio e inesperado ao mostrar-nos que seu projeto/tese sobre a Motricidade Humana tem muitos enfrentamentos pela frente. Fazer o desporto transcender de sua posição espetacular e mercadológica para um estado de jogo, humor, festa, cultura, não é fácil. E ele ainda questiona: “[...] não será [isso] difícil em clubesempresas, com o domínio quase absoluto das forças do mercado, onde as relações clube-adepto sofrem de hesitações e equívocos, porque o espírito empresarial se sobrepõe à afectividade dos sócios e simpatizantes [?]” (Ibidem, p. 261). Ou ainda, “[...] os clubes podem ser simulacros de valores humanizantes se não têm na devida conta a saúde dos atletas, a sua justa [...] remuneração, a sua integração familiar e social” (SÉRGIO, 2003, p. 63).

A resposta para essa pergunta pode estar na certeza de que as problemáticas no âmbito do desporto são as problemáticas sociais de uma forma geral. Não se trata de um microcosmo paralelamente produzindo uma mimese do macrocosmo social. A democracia ideal (governo do povo) não existe de fato em lugar algum da sociedade moderna. A população de uma maneira geral não governa, pois seus corpos estão excluídos dos espaços de poder. Os recentes anos de democracia brasileira mostraram que quem governa é quem está de corpo presente nos lugares de poder. O voto destinado ao corpo do outro enquanto representante de nosso próprio, de modo algum é capaz de assumir a potência da motricidade mesma materializada no corpo. Assim sendo, é possível afirmar com Manuel Sérgio (1995, p. 90) que quem assume “[...] a democratização do desporto, na Europa [assumimos que no Brasil também], é praticamente [o] Estado e que este se mostra mais interessado no apoio à alta competição do que no 
fomento de qualquer tipo de desporto”. Algumas provas atuais disso foram os esforços políticos, econômicos, temporais e geográficos que o Governo Federal do Brasil empenhou na realização dos XV Jogos Pan-Americanos de 2007 na cidade do Rio de Janeiro entre os dias 13 e 29 de julho ${ }^{3}$.

Por fim, Manuel Sérgio não demonstra desejar resolver essas questões de uma vez por todas, pois expõe a sabedoria acerca do risco que se corre ao desejar resolver tudo de uma vez por todas: a inclinação à arbitrariedade e ao fascismo. Para tanto, a Ciência da Motricidade Humana não é uma tese que garante soluções, mas sabiamente se trata de um exercício ético por meio do qual o humano pode avaliar a situação atual de sua corporeidade e motricidade, que é de crise. A pergunta que nos assalta é: qual é o sentido da crise? Ou ainda: quais as possibilidades que podem advir da crise? Para nosso filósofo da Motricidade Humana, o que existe é um “[...] tetragrama: ordem-desordem-interações-organização” (SÉRGIO, 2003, p. 48). Lembrando Edgar Morin: "Este tetragrama não dá a chave do universo. Permite apenas compreender como funciona. Revela-nos a complexidade. [...] É [...] dialogar com o mistério do mundo” (MORIN, apud loc. cit.). Ora, e o humano dialoga, por excelência, por meio de sua motricidade, ou seja, “[...] o corpo em acto, [...] espaço de signos e de onde emergem a carne, o sangue, o desejo, o prazer, a paixão, a rebeldia, emoções e sentimentos do mais variado tipo. E tudo isso visando a transcendência [...]” (Ibidem, p. 49). Transcendência no corpo e pelo corpo.

\section{Referências}

BENGHI, J. R; ZOBOLI, F. Educação física e promoção bumana. Blumenau: Acadêmica, 2004.

FERRAZ, M. S. A. O corpo em Merleau-Ponty: a dimensão carnal do mundo. In: Mente, cérebro e filosofia: fundamentos para a compreensão contemporânea da psique. São Paulo: Ediouro, Segimento-Duetto Editorial Ltda., número 5, 2007.

\footnotetext{
${ }^{3}$ Não iremos aprofundar as implicações políticas e econômicas desse evento. Mas cabe alertar que a escrita deste texto foi realizada no período dos XV Jogos Pan-americanos 2007.
} 
LAPLANTINE, F. Aprender antropologia. Tradução de Marie-Agnès Chauvel. São Paulo: Editora Brasiliense S.A., 1996.

MEDINA, J. P. S. O brasileiro e seu corpo: educaşão e política do corpo. $2^{\circ}$ ed. Campinas, SP: Papirus, 1990.

MERLEAU-PONTY, M. Fenomenologia da percepção. Tradução de Carlos Alberto Ribeiro de Moura. $2^{\circ}$ ed. São Paulo: Martins Fontes, 1999.

. O visivel e o invisivel. 3 ed. São Paulo: Editora Perspectiva, 1992.

NIETZSCHE, F. Assim falou Zaratustra. Tradução de Alex Marins. São Paulo: Martin Claret, 2005.

. A gaia ciência. São Paulo: Companhias das Letras, 2001.

RAMACCIOTTI, B. L. O corpo em Nietzsche: a filosofia como arte da transfiguração. In: Mente, cérebro e filosofia: fundamentos para a compreensão contemporânea da psique. São Paulo: Ediouro, Segimento-Duetto Editorial Ltda., número 4, 2007.

SÉRGIO, M. Alguns olhares sobre o corpo. Coleção: epistemologia e sociedade. Lisboa - Portugal: Instituto Piaget, 2003.

Um corte epistemológico: da educação física à motricidade bumana. Coleção: Epistemologia e sociedade. Lisboa - Portugal: Instituto Piaget, 1999.

Motricidade humana: um paradigma emergente. Prefacio de Ubirajara Oro. Blumenau: Editora da FURB, 1995.

SILVA, R. I da; ZOBOLI, F. Corpo e poder na formação da Igreja e do Estado. In: $18^{\circ}$ Encontro de Pesquisa Educacional do Norte e Nordeste: politica de ciência e tecnologia e formação do pesquisador em educação. 2007. 